\title{
Using self-generated analogies in teaching of thermodynamics
}

\author{
Jesper Haglund and Fredrik Jeppsson
}

\section{Linköping University Post Print}

\begin{abstract}
N.B.: When citing this work, cite the original article.
\end{abstract}
This is the authors' version of the following article:

Jesper Haglund and Fredrik Jeppsson, Using self-generated analogies in teaching of thermodynamics, 2012, Journal of Research in Science Teaching, (49), 7, 898-921.

which has been published in final form at:

http://dx.doi.org/10.1002/tea.21025

Copyright: Wiley-Blackwell

http://eu.wiley.com/WileyCDA/Brand/id-35.html

Postprint available at: Linköping University Electronic Press

http://urn.kb.se/resolve?urn=urn:nbn:se:liu:diva-79919 


\title{
Using Self-Generated Analogies in Teaching of Thermodynamics
}

\author{
Jesper Haglund and Fredrik Jeppsson \\ The Swedish Natural Graduate School in Science, Technology and Mathematics Education, \\ Linköping University, SE-60174 Norrköping, Sweden
}

\begin{abstract}
Using self-generated analogies has been proposed as a method in a constructivist tradition for students to learn about a new subject, by use of what they previously know. We report on a group exercise on using self-generated analogies to make sense of two thermodynamic processes, reversible adiabatic expansion and free adiabatic expansion of an ideal gas. The participants $(\mathrm{N}=8)$ were physics preservice teacher students at the fourth year of the teacher education program. A main finding was that work with self-generated analogies tended to be accompanied by the students assuming ownership for their learning, manifested in terms of actions of choice and control and the use of exploratory talk. Consequently, several self-generated analogies were elaborated and developed to a high order relational structure. However, we also found that with the use of selfgenerated analogies in science teaching follows the risks of developing idiosyncratic explanations of the encountered phenomena or getting stuck in overly complex comparisons.
\end{abstract}

Sammanfattning: Självgenererade analogier har förts fram som en metod i en konstruktivistisk tradition för att elever och studenter ska kunna lära sig något nytt genom att relatera till vad de redan vet. Vi redogör här för en gruppövning där självgenererade analogier användes för att förstå två termodynamiska processer: reversibel adiabatisk expansion, respektive fri adiabatisk expansion av en ideal gas. Åtta $(\mathrm{N}=8)$ lärarstudenter på fjärde året av utbildningen med inriktning mot fysik på gymnasiet deltog i studien. Ett viktigt resultat var att vid arbete med självgenererade analogier tenderade studenterna att ta ägandeskap för sitt lärande, vilket tog sig uttryck i handlingar såsom aktiva val, kontroll över processen och explorativ dialog. Som en följd utvecklades flera av de självgenererade analogierna till ett stort strukturellt djup. Samtidigt såg vi att vid skapande av egna analogier löper studenter risken att utveckla egna förklaringar av de studerade fenomenen som inte svarar mot dem inom vetenskapen eller snärja in sig i alltför komplexa jämförelser.

Keywords: self-generated analogies; group work; thermodynamics; ownership of learning

\section{Introduction}

Thermodynamics is a fundamental part of physics and chemistry that is encountered by many students at the undergraduate level. Yet, many of the core concepts in thermodynamics, such as entropy and temperature, are considered to be abstract and difficult for novices to grasp. In the present study, we invited eight physics preservice teacher students to generate analogies for two thermodynamic processes, working in groups of four. We set out to investigate the difference between interpreting an analogy provided from outside, by a teacher or in a textbook, and creating your own analogy for a phenomenon.

Below, we first outline how analogies are used in science education, but also account for the risks with such approaches. In addition, we expand on how the self-generated analogies has been proposed as a way to come to terms with some of those risks, as exemplified with empirical educational studies. Next, we give an account of how students' ownership of learning has been introduced in science education and, finally, we detail particular findings regarding teaching and learning in thermodynamics.

\section{Analogies in Science Education}

One way of introducing abstract concepts in education is to use analogies. Gentner's Structure Mapping Theory (1983) has been used extensively in science education to account for the nature of analogical reasoning. The purpose of teaching with analogies is that the students will learn about a new object of study, a target domain, by comparison with another, more familiar source domain. Conclusions are made with regards to the source domain and transferred to the target domain. Analogical reasoning depends on structural similarities 
between the domains. As an example, 'the atom is like a solar system' is an analogy where the abstract, invisible and presumably less familiar atomic structure is compared to the more concrete and familiar domain of celestial bodies in motion. Structural similarities are that electrons correspond to planets, which orbit around a larger atomic nucleus and star, respectively, and that there is a large void space in between. Also the mathematical formalism in Newton's gravitational force and Coulomb's law can be compared, where electrical charges correspond to the mass of objects and the forces are proportional to the inverse of the distance squared. However, attributes or surface features should not be focused upon, such as drawing the conclusion that since the sun is yellow and warm, so is the atomic nucleus.

Since an analogy is a representation of a phenomenon, where certain characteristics are emphasised and others are played down, it is never a perfect image. Glynn (1989) points out:

Teachers and authors should explain to students that analogies are double-edged swords. An analog can be used to correctly explain and even predict some aspects of the target concept. At some point, however, every analogy breaks down. At that point, miscomprehension and misdirection can begin.

In this respect, analogies in science teaching are similar to scientific models, which only account for certain aspects of a phenomenon in the physical world. As an example, the solar system as an analogue model of the atom structure does not provide useful explanations from a quantum physics point of view. Spiro, Feltovich, Coulson and Anderson (1989) propose that one way of handling the idiosyncratic features of individual analogies is to present multiple analogies which complement each other. Heywood and Parker (1997) take a different perspective on the breakdown of analogies and argue that it contributes to conceptual understanding, but also gives an authentic view of the scientific enterprise: "[I]t is in the promotion of the critical scrutiny in challenging the analogy, attempting to apply it and recognising when and why it breaks down that the opportunity for learning really takes place." They also show that an analogy where many corresponding concepts are identified in the source and target domains produces a rich discussion.

\section{Self-Generated Analogies}

Blanchette and Dunbar (2000) have reviewed experimental studies of problem solving where subjects are presented with problems in different domains but with similar underlying structures, so that they would be suitable for analogical reasoning. However, the subjects tend to focus on surface similarities, and fail to recognise the intended structural relations. This may be contrasted with our everyday life, in research, and as students in school, where analogical reasoning based on shared structures often is used spontaneously (e.g. Clement, 1987, 1988). The discrepancy between our spontaneous use of analogical reasoning and failure to recognise structural relations in taught analogies may seem as a paradox, but Blanchette and Dunbar argue that it may be resolved by contrasting a reception paradigm with a production paradigm. In the reception paradigm, learners are supposed to receive an already existing analogy and interpret and use it in an intended way. This brings along two challenges: firstly, that the subjects are supposed to have in-depth knowledge of the source domain, and secondly; that they have to identify the similarity of the domains. In the production paradigm, on the other hand, the learner him- or herself creates or generates analogies in order to organise what is known about a studied phenomenon. By default, the source domain and how it is linked to the target is grasped by the learner, otherwise it would not be considered as useful. We regard spontaneous analogy as the use of analogy when exploring a new area spontaneously, without being cued by a teacher or researcher, while selfgenerated analogy is the generation of a new analogy, by request from a teacher or researcher.

Wilbers and Duit (2006) shed light on the difference between the psychological process of a teacher or textbook author that designs a suitable instructional post-festum analogy for a 
phenomenon and the learner or researcher approaching a target domain by means of a heuristic analogy, that "aims at the construction of analogical relations rather than the detection of objectively and antecedently existing correspondences". Wilbers and Duit argue that this creative aspect of analogical reasoning has received limited attention in the tradition following Gentner's Structure Mapping Theory (1983). However, in our view the main feature of heuristic analogies, i.e. that the knowledge of the two domains and their relations develop as the analogy is created, is also captured in the process of analogical bootstrapping (Kurtz, Miao, \& Gentner, 2001) where two only partially known domains are explored by comparing them to each other. Pittman (1999) notes that the teaching by analogy has been proposed by using argumentation along the lines of constructivism, with the basic assumption that learning can take place only in relation to the pre-existing knowledge of the learner. In spite of this constructivist stance, most studies on the use of analogies in science education research have been performed on teacher-generated analogies, where the students' previous knowledge is only assumed implicitly. However, there are some examples of empirical studies on the use of self-generated analogies within a production paradigm, which seems to fit more naturally with a constructivist perspective.

In physics teaching, Wong (1993a, 1993b) performed an experimental study on 11 secondary school teacher candidates who were asked to explain three air pressure phenomena, formulate areas where their explanations were inadequate and come up with self-generated analogies as a tool to attain a better understanding. James and Scharmann (2007) performed a study on a course on methods for teaching science for preservice elementary teachers, where a treatment group was introduced to generation of analogies, asked to find analogies for rocket propulsion in order to explain Newton's Third Law in group exercises and to construct practice lessons based on the analogies. A control group was taught to develop explanations by eliciting students' ideas prior to teaching, which was used to develop lessons for force and motion concepts in group exercises, but scored significantly lower in post-tests on conceptual understanding. In biology teaching, Pittman (1999) performed a study on students in grade 7 and 8 , who took a two week unit on protein synthesis in their regular science class. After one week of regular instruction and introduction to analogies, the students worked in groups of three or four to create their own analogies for protein synthesis. As a conclusion, studentgenerated analogies were seen as a useful tool for assessment of students' conceptions and for formative assessment. In chemistry teaching, Mozzer and Justi (2011) report on a study where 13- to 14-year-olds were asked to generate analogies for chemical bonding in clinical interviews before and after a teaching sequence on the subject. In the interviews after the teaching, the students were able to identify limitations in the analogies they had generated beforehand, corresponding to the acquired knowledge, and elaborate them, e.g. by incorporating repulsive forces between atoms in a molecule in their analogies. Outside science teaching, Blanchette and Dunbar (2000) performed a study on analogical reasoning, where the issue of achieving zero budget deficit in financial politics was the target domain for learning. Undergraduate students were found to be able to generate their own analogies that focused on relational structures, rather than on surface similarities. The results were similar after both individual and group exercises.

More recently, the social dimension of generation and scrutiny of analogies in discourse has received increasing attention. Yerrick, Doster, Nugent, Parke and Crawley (2003) studied preservice physics teachers working with analogies for electric circuits in small group exercises within a guided-inquiry approach. While strategically inserted teacher-generated analogies effectively led the students to ascertain their own beliefs, when the analogies were adapted in small-group discussions, they tended to promote misconceptions and to be overgeneralised in contexts where they did not apply. In particular, self-generated analogies, corresponding to the students' personal theories were found to divert them from the focus on 
the studied phenomena, lead to incorrect conclusions, and unconstructive group dynamics. On a happier note, Aubusson and Fogwill (2006) studied the effect of inviting secondary chemistry students to cooperate in the development of a role play as an analogy of a process involving formation and dissolution of chemical bonds, where the students acted as atoms and ions. They found this approach to offer an opportunity for the students to express, negotiate and develop their understanding in conversation as the analogy role play developed, encompassing new features gradually throughout the course of three lessons. Similarly, Bellocchi and Ritchie (2011) investigated the use of analogy role play and analogy generation in small group work among secondary chemistry students. They found such exercises to stimulate hybridisation between the students' own experiences from their everyday life and the scientific accounts of the studied phenomena, expressed as merged discourse and generation of hybrid, so called portmanteau words. For instance, a happy person representing a positively charged ion merged into a novel 'perso-ion'. Another case was a word play, pronouncing the neurotransmitter GABA as 'gaybar', which inspired an analogy between the phenomenon involving GABA and the students trying to sweet-talk themselves into a club.

As a contrast to these findings predominantly in favour of the production paradigm, Clark (2006) is cautious that in such constructivist approaches, students may spend too much time on their idiosyncratic explanations, rather than building a conception in line with the position in science. Supported by Yerrick et al.'s (2003) findings, Zook (1991) warns that education research has not sufficiently acknowledged the risk of students developing misconceptions as a consequence of teaching with analogies. Zook predicts that the process of mapping the source and target domains is particularly problematic in the case of teacher-generated analogies, but for analogies generated by the learners the most difficult process is the selection of appropriate source domains.

\section{Ownership of Learning}

Dudley-Marling and Searle (1995) introduced the concept of student ownership of learning in literacy education, accounting for students' independence, autonomy, and choice. In the context of a collaborative business communication course, Savery (1996) developed a set of behavioural indicators of ownership for learning, drawing on four categories of psychological factors: metacognitive and cognitive factors, emphasising self-regulation; affective factors; personal and social factors; and individual differences factors. MilnerBolotin (2001) investigated ownership in the setting of university physics group project work from the point of view of the individual learner, in which a learner has a high degree of ownership of a project if he or she: finds personal value in pursuing the project in terms of understanding how knowledge in the area might be useful and how it connects to previous understanding; feels in control of the process in terms of making decisions, and; takes responsibility for the learning process and its result.

Enghag and colleagues (Enghag, Gustafsson, \& Jonsson, 2009; Enghag \& Niedderer, 2008) have developed ownership of learning as a theoretical framework and operationalised it in their analysis of group work in university physics education, following the approach of Savery (1996) in identifying behavioural indicators rather than limiting ownership to covert psychological mechanisms. Overall, they define ownership as "actions of choice and control taken by the students during group work" (Enghag \& Niedderer, 2008). Enghag and Niedderer (2008) studied physics teacher students working in small groups with mini-projects in electrodynamics. While Milner-Bolotin (2001) focuses on the individual's ownership of learning in group work, Enghag and Niedderer argue that it has to be complemented by the perspective of the group. In the categorisation of the empirical data, they analysed students' actions from the point of view of autonomy, control and choice, i.e. the perspective of Dudley-Marling and Searle (1995), but found them acting at the collective level. Hence, 
choosing a task that was found interesting and at an appropriate level of complexity, organising the work and agreeing on how to present the findings contributed to group ownership of learning. At the same time, Enghag and Niedderer acknowledge the dimension of the individual student ownership of learning, characterised by a student bringing in to the group discussion an own idea, question or problem, often based on own experiences or difficulties in understanding the studied topic; coming back persistently to it throughout the group work; and finally developing insight by resolving the issue. Enghag, Gustafsson and Jonsson (2009) studied ownership of learning among engineering students in small-group work with open-ended context-rich problems that relate to everyday life situations and lack some information, so that assumptions are required. Group ownership of learning was here primarily indicated by exploratory talk, where students keep a focus on the subject and task at hand in an exploratory fashion, characterised by common use of half sentences and filling in the others' missing words, questioning, challenging, encouraging and drawing each other into the discussion. Cases of individual ownership of learning were less frequent in this study, compared to the approach with mini-projects.

\section{Learning of Thermodynamics}

Thermodynamics is the field of science that studies transfer and transformation of energy when different types of systems interact with one another or with their surroundings. An important part of learning thermodynamics is to be able to describe different kinds of processes involving such changes of systems. Fundamentally, the first law of thermodynamics states the conservation of energy. The second law states that energy tends to dissipate, for instance from one system of higher temperature to a system of lower temperature; in addition, all irreversible changes in nature are accompanied by increasing entropy.

Baierlein (1994) suggests that there are generally two approaches to teach introductory thermodynamics. On the one hand, a historical and macroscopic approach can be adopted that focuses on properties of cyclic processes, where concepts such as entropy and temperature are introduced as state functions. This provides good opportunities for problem solving in engineering, but gives limited understanding of the nature of the involved quantities. On the other hand, a microscopic statistical mechanics approach involves the introduction of a system-particle model and the concept of microstates, offering a deeper understanding of the involved quantities. Here, the challenge is how to proceed from the abstract physical model to macroscopic applications. Reif (1999) argues in favour of a microscopic atomistic approach and emphasises the need to understand the underlying mechanisms of physical phenomena. In addition, he points out the difficulty among students to build visualizable mental models with a macroscopic approach. In contrast, Loverude, Kautz and Heron (2002) claim that students tend to apply microscopic models in inadequate ways, and propose that concepts have to be firmly understood in macroscopic contexts first, using for example bicycle pumps.

Several analogies have been used in teaching macroscopic thermodynamics, many of which build on Carnot's comparison of heat flow with a waterfall, where the flow of water corresponds to a flow of heat or entropy, driven by a potential difference in height corresponding to temperature (e.g. Fuchs, 1987; Kaper \& Goedhart, 2005). When it comes to microscopic approaches, billiard ball models, where the colliding balls correspond to interacting gas particles, have been used in the development of the kinetic theory of gases (Hesse, 1966). Another common microscopic analogy is to compare a thermodynamic system and its particles to a messy room with its toys and pieces of clothing, where high entropy is put forward as corresponding to the state of disorder. However, we have shown that the word entropy and words commonly used in analogies for entropy have many senses. Such semantic ambiguity adds further to the challenge of learning abstract concepts, in this case entropy (Haglund, Jeppsson, \& Strömdahl, 2010; Jeppsson, Haglund, \& Strömdahl, 2011). In 
particular, seeing entropy as disorder has been criticised for its 'snap-shot' view and exclusive focus on spatial configuration (Lambert, 2002).

Empirical studies have found that university students have difficulties grasping the concepts of entropy and temperature and applying microscopic models in problem solving. Brosseau and Viard (1992) asked ten PhD students in physics what happened to the entropy in reversible, adiabatic expansion, i.e. not involving heat exchange with the surroundings, of an ideal gas. Only one of the students grasped that the entropy is constant in the process. Seven of the students argued that as the volume increases, so does the disorder, and hence, also the entropy. In this way, by seeing entropy as disorder, the students encompassed the contribution of spatial configuration to the entropy alone and failed to realize the energy contribution, giving support to the view of Lambert (2002). Supporting Loverude et al. (2002), Leinonen, Räsänen, Asikainen and Hirvonen (2009) found that undergraduate physics students tend to misapply microscopic models in problem solving exercises. For instance, students were found to see collisions of particles as the cause of temperature or that energy was released as a consequence of the collisions. Regarding temperature, Bucy (2007) used a problem solving exercise on free expansion of an ideal gas, where some of the students declared that the temperature would decrease in the process, in spite of the fact that the temperature was stated to remain constant throughout the process. In addition, Loverude et al. (2002), Meltzer (2004) and Leinonen et al. (2009) have found that students have difficulties disambiguating internal energy and temperature, due to their close connection in the kinetic theory of gases.

\section{Purpose of Research}

This study is part of an investigation of how self-generated analogies may be used to develop and express the understanding of thermal phenomena, particularly of the concept of entropy, among university students. Due to entropy being a difficult concept and often regarded as abstract, we find it suitable for introduction with the help of analogy, by reference to other, more concrete domains. Previous research related to in the literature review has identified that asking students to come up with their own analogies fits well within a constructivist framework and has, in many occasions, led to significantly better learning when compared with other teaching approaches. In our research, we aim to contribute to understanding how and why generation of your own analogies is conducive to learning. In addition, we are interested in the influence of group work on the generation of analogies. Accordingly, in the present study, we addressed the following research questions:

(1) How do students perform analogical reasoning in a group exercise when they are asked to come up with analogies for thermal phenomena?

(2) How is ownership of learning manifested as students come up with analogies?

\section{Method}

\section{Participants}

The participants were eight preservice teacher students $(\mathrm{N}=8)$, specialising in mathematics and physics teaching, studying at the fourth year of the teacher training program for upper secondary teachers at a Swedish university. The rationale for selecting teacher students was that, in comparison to e.g. engineering students, they had been trained to reflect upon and communicate about epistemological issues in general and particularly on how physical phenomena may be represented in models and analogies in their future teaching. Previously, the students had taken courses in maths and maths teaching for a year and a half. In the weeks before the study, they had all taken a physics course in mechanics and thermodynamics, including a brief introduction to particle models in the kinetic theory of gases and the concept of microstates by use of University Physics (Young, Freedman, \& 
Sears, 2003), but not an in depth account of statistical mechanics including the connection between energy levels and microstates. In the physics course, the lecturer emphasised conceptual understanding and made extensive use of analogies in the teaching, but the participants had not experienced generating their own analogies or exploring where analogies break down in group work. The study was not part of the standard coursework and the students volunteered freely, but received a small token of appreciation for the participation.

\title{
Research Design
}

The students were given a short oral and written introduction by the researchers on the use of analogies in teaching, Gentner's (1983) structural perspective on analogies and possible pitfalls with analogies as a teaching approach. (Additional information on the introduction is available as supplementary material accompanying the online article.) Next two thermal processes were presented: reversible adiabatic expansion of an ideal gas, and; free adiabatic expansion of an ideal gas. The students were provided with the following descriptions of the two processes in writing:

\begin{abstract}
Process 1. Adiabatic expansion. An ideal gas is kept in a container by a frictionless piston. The gas has amount of substance $n$, temperature $T$, internal energy $U$, pressure $p$, volume $V$ and entropy $S$. Let the gas expand slowly, adiabatically (i.e. no heat $Q$ is exchanged with the environment) and reversibly (i.e. so that the process "can go in the other way" to restore the original state) by retracting the piston. As the piston retracts, work $W$ is performed by the gas on the environment, which means that the internal energy $U$ of the gas decreases. At the same time, the volume $V$ increases and the pressure $p$ decreases. The temperature $T$ decreases. The average velocity of the gas particles decreases, because they will have a lower velocity after collisions with the withdrawing piston. The entropy does not change during the process, since no heat has been exchanged with the environment and the process is reversible, a situation represented by the following relation: $d S=d Q / T$.
\end{abstract}

Process 2. Free expansion. An ideal gas is kept in one half of an isolated container separated by a thin wall. There is a vacuum in the other half. The gas has amount of substance $n$, temperature $T$, internal energy $U$, pressure $p$, volume $V$ and entropy $S$. After the instantaneous removal of the wall, the gas expands freely in the entire container. No work $W$ or heat $Q$ is exchanged with the surroundings, and hence, the internal energy remains constant. As a result, the volume of the gas is doubled and the pressure is halved. Since the particles collide with the stationary walls, their average velocity does not change. The temperature $T$ is constant, but the entropy $S$ increases.

The intention was that the descriptions should bring across what happened in the processes, but leave as a 'stretched target' for the students to figure out how and why it happened. As a hypothesis, we expected that it would be challenging for the students to account for why the entropy remains unchanged in Process 1 , in spite of increased volume, by reference to the findings of Brosseau and Viard (1992). In Process 2, the main challenge for them was expected to be explaining why the temperature remains the same, even though the volume increases, as identified by Bucy (2007). The design of the task adheres to the instructional tactic of completion problems, where the participants are supposed to fill in a gap on the way to a given end state (van Merriënboer, Shuurman, de Croock, \& Paas, 2002). In our case, the tasks were considered to have been too difficult for these students if the constant entropy and temperature in the two processes, respectively, had not been stated. The students would likely have ended up with wrong values of these quantities and would not have been encouraged to discuss further.

As seen in the Introduction, many previous studies on analogical reasoning have had a focus on individuals and the assessment of learning gains, either in the form of clinical interviews with a researcher or in written pre-/posttests. In the present study, however, we chose to let the participants work together in groups, in order to uncover their ideas in discourse in a situated practice (cf. Schoultz, Säljö, \& Wyndhamn, 2001). In our view, this 
approach fits well with the overall purpose of the research to explore how students use analogical reasoning in problem solving and why self-generated analogies may be conducive to learning. Specifically, we followed the approach of Enghag and colleagues (Enghag et al., 2009; Enghag \& Niedderer, 2008) in using group work as a form to make students assume ownership for their learning. The participants were divided in two groups of four in each, S1, S2, S3 and S4 in Group A and S5, S6, S7 and S8 in Group B. The students were given the instructions to establish a shared view on the processes within the group and identify what is difficult to understand. They were also instructed to come up with analogies for the processes, with a particular emphasis on entropy, and select a few of them for presentation to the researchers and to the other participants. The intention was for the students to find source domains and establish how the structures were similar to the two processes. The groups sat in individual rooms and were provided with working material such as the processes and tasks in writing, paper and pencil, and a white board in order to be able to share their ideas. This group work session lasted for one hour and the researchers were not present, except for short check-ups on the progress. The approach of letting the participants work together in groups with minimal intervention by the researchers reflected an ambition of stimulating dialogue among the participants. Next, for half an hour, the groups presented the selected analogies and received feed-back from the other group and the researchers, regarding how well the analogies reflected the phenomena and the involved concepts. After the presentations, the researchers informed the groups orally that microstates relate not only to spatial configuration of particles, but also to the distribution of energy across discrete energy levels, since this was perceived by the researchers as a necessary input for further progress. Now, the participants reassembled in the original small groups to modify the analogies or come up with new ones, based on the feed-back on their presentations. Finally, everybody gathered for a round-table discussion on how analogies can be used in education, assuming a teacher perspective. In all, the exercise took three hours and the sessions where the students generated, presented and modified the analogies, and the round-table discussion were audio and video recorded.

\section{Data Collection and Analysis}

The audio records were transcribed in all and the coding was managed through using the MAXQDA software. Our study differed from that of Blanchette and Dunbar (2000) in that we used a group work exercise and that we did not use self-generated versus teacher-generated analogies as different conditions in parallel set-ups for comparison. However, we followed their approach in analysing the following dimensions of the generated analogies:

- Degree of similarity between source and target. We used the following categories for the source domain: anthropomorphic; dead objects, and; physics.

- Structural depth. To discern different relational structures, we used Gentner's (1983) distinctions between attributes, first-order relational structure and higher-order relational structure. Attributes are statements taking in only one argument and focusing on surface similarities. In the example 'the hydrogen atom is like our solar system', attributes would be that the sun is yellow or hot. First-order relational structures are comparable to causal reasoning, e.g. if X thus Y. Higher-order relational structures are characterized by several interrelated concepts, e.g. if $\mathrm{X}$, given that $\mathrm{Y}$ and $\mathrm{Z}$ fulfil certain conditions, then $\mathrm{W}$.

- The explicitness of the analogies were coded as: not developed, if only one utterance with no explicit connection to the target was mentioned and not further elaborated; implicit, for which no elements of the target were mentioned; partially explicit, if a few elements stated in the source had counterparts in the target, and; explicit, if all (or a large majority of the) elements stated in the source had an identified counterpart in the target. 
Apart from these dimensions, we were also interested in looking at what senses of entropy (Haglund et al., 2010) the groups focused on in their analogies. Did they assume a macroscopic perspective, a microscopic particle perspective or use the disorder metaphor implicitly? In addition, the following categories, which developed in a bottom-up fashion during the analysis work, were used to code the analogies:

- Initiating group. Did group A or group B bring up the analogy? Separate records were made if both groups came up with a similar analogy.

- Origin. Whether the analogies were originated by the group itself or provided previously by teacher or from literature. Several analogies were explicitly taken from the previous course on thermodynamics. Some other analogies may have been heard in previous teaching, but without direct reference to the previous teaching.

- Number of physical quantities covered in the analogy, e.g. entropy and pressure.

- Number of other concepts covered, e.g. reversibility and the ideal gas law.

- Number of challenges, comprising a combination of difficult issues, e.g. explaining the constant temperature at free expansion, and misconceptions, e.g. the belief that collisions are required to maintain the temperature.

- Number of statements. A statement, a stretch of verbal output from one individual person, was our smallest unit of analysis.

Finally, as part of the bottom-up analysis of the transcripts of the students' dialogues, we also identified the theme of 'ownership of learning' as a potential explanatory factor for the difference between the self-generated and teacher-generated modes of analogical reasoning. We therefore analysed the students' dialogues from this point of view, by identifying instances of the behavioural indicators developed for similar contexts of group work in physics among university students (Enghag et al., 2009; Enghag \& Niedderer, 2008):

- Actions of choice and control regarding the task, organisation and presentation of the work, manifested as exploratory talk, contributing to group ownership of learning.

- A question or dilemma of personal interest is brought up, returned to throughout the process and eventually leading to new insight in terms of a deeper physics understanding, characteristics of individual student ownership of learning.

\section{Results}

\section{General Overview}

Overall, the discussions in the two groups went on well and the participants came up with many analogies for the two processes. In all, group A initiated the discussion of 20 analogies (out of which four were not elaborated and are excluded in the further analysis) and group B initiated 12 (one not elaborated and excluded). Both groups demonstrated the capability of coming up with more than one higher relational structure analogy and several more first order relational structure analogies, primarily from domains far from the studied phenomena. Group A came up with more analogies than group B, but on average their analogies were slightly less elaborated, as can be seen in the lower numbers of average concepts and challenges covered. Group B's considerably larger total amount of statements related to analogies reflects that they spent most of the time elaborating one analogy ('angry bees', which covered 857 of the statements), while group A spent more time of their group session on understanding the processes without relating them to analogies.

The analogies can be classified by origin as shown in Table 1. A majority of the analogies were originated by the groups themselves, but 10 out of 27 were taken from previous teaching. Interestingly, however, the groups elaborated their new, own analogies 
more than the previously known analogies, as seen in the larger amount of concepts covered, the qualitatively deeper structural level and the considerably larger amount of statements.

Table 1

Characterisation of the generated analogies, divided by group

\begin{tabular}{lcc}
\hline Group & A & B \\
\hline Total number of analogies & 16 & 11 \\
$\quad$ Attributes & 8 & 6 \\
$\quad$ First order structure & 5 & 3 \\
$\quad 3$ & 2 \\
Avigher order structure & 2.4 & 2.7 \\
Average number of quantities & 0.4 & 0.9 \\
Average number of challenges & 0.9 & 1.7 \\
Total number of statements & 622 & 1081 \\
\hline
\end{tabular}

All 27 analogies used a microscopic approach with sources that shared the structure of components comprising a system or a whole. In addition, many of the analogies used the idea of entropy as disorder, but the implicit nature of the metaphor makes it difficult to quantify the extent of its use. However, none of the analogies was based on quantitative relations between central macroscopic quantities, for instance reminding of Carnot's waterfall analogy. In our view, the fact that all analogies were based on a microscopic perspective is interesting, particularly due to the primarily macroscopic focus of the previous thermodynamics course.

In all, 23 different challenges were identified, including the two challenges inherent in the design, i.e. explaining the constant entropy in reversible adiabatic expansion and the constant temperature in free adiabatic expansion. Four other challenges also influenced the discussions of both groups to a large degree: understanding what entropy means; understanding what a microstate means; understanding the connection between entropy and microstates, and; understanding the influence on the temperature of collisions. At the start of the exercises, the groups expressed an interpretation of microstates as exclusively related to spatial configuration, ignoring the contribution of energy or energy levels, which in turn made the constant entropy of Process 1 puzzling, much in agreement with the findings of Brosseau and Viard (1992). In order to explain the constant entropy, both groups developed the hypothesis that entropy is linked to the change of microstates, rather than to the number of microstates as such, i.e. a case of idiosyncratic explanations being formed as pointed out by Clark (2006). However, as mentioned, in the group presentation session, they were given the input that microstates relate to energy levels. By the end of the second round of refining the analogies, the groups had managed to come to terms with five of these six challenges, the exception being the consequence of collisions, which is detailed in the 'angry bees' analogy below.

\section{Examples of Analogies}

Below we present the four analogies with which the students spent most time and which were elaborated to the greatest structural depth. They also represent a large variety across many of the different dimensions identified in the study, e.g. self-generated vs. teacher- 
generated analogies. Table 2 details the correspondences made between central thermodynamic concepts and concepts in the generated source domains.

Table 2

Explicit correspondences between concepts in the thermal domain and the four analysed analogies

\begin{tabular}{|c|c|c|c|c|}
\hline $\begin{array}{l}\text { Concept in target } \\
\text { domain }\end{array}$ & $\begin{array}{l}\text { Analogy 1. Angry } \\
\text { bees }\end{array}$ & $\begin{array}{l}\text { Analogy } 2 . \text { People } \\
\text { at a party }\end{array}$ & $\begin{array}{l}\text { Analogy } 3 \text {. Models } \\
\text { of balls }\end{array}$ & Analogy 4. Lice \\
\hline Particles & Bees & Persons & Balls & Lice \\
\hline Volume & Volume & $\begin{array}{l}\text { Floor surface and } \\
\text { discrete set of seats }\end{array}$ & Volume & $\begin{array}{l}\text { The heads and hair } \\
\text { of two persons }\end{array}$ \\
\hline Pressure & $\begin{array}{l}\text { 'Impact' of } \\
\text { collisions with } \\
\text { other bees and } \\
\text { walls }\end{array}$ & $\begin{array}{l}\text { Vaguely related to } \\
\text { crowdedness and } \\
\text { bouncing into each } \\
\text { other }\end{array}$ & $\begin{array}{l}\text { Frequency and } \\
\text { 'impact' of } \\
\text { collisions }\end{array}$ & $\begin{array}{l}\text { Frequency of bites } \\
\text { per area unit }\end{array}$ \\
\hline Temperature & Angriness & $\begin{array}{l}\text { Eagerness to get a } \\
\text { seat }\end{array}$ & Function of velocity & - \\
\hline Velocity & Velocity & Velocity & Velocity & Speed of jumps \\
\hline Energy & Angriness & $\begin{array}{l}\text { Eagerness to get a } \\
\text { seat }\end{array}$ & Function of velocity & Conserved quantity \\
\hline Microstates & $\begin{array}{l}\text { Initially: Spatial } \\
\text { configuration } \\
\text { Finally: Spatial } \\
\text { configuration and } \\
\text { energy distribution }\end{array}$ & $\begin{array}{l}\text { Spatial } \\
\text { configuration of } \\
\text { seats }\end{array}$ & - & - \\
\hline Entropy & $\begin{array}{l}\text { Logarithm of } \\
\text { microstates }\end{array}$ & $\begin{array}{l}\text { Finally: Vaguely } \\
\text { related to } \\
\text { configuration of } \\
\text { seats and eagerness }\end{array}$ & - & Disorder \\
\hline Degrees of freedom & $\begin{array}{l}\text { Axes of rotation in } \\
\text { flight }\end{array}$ & - & - & - \\
\hline
\end{tabular}

As seen in Table 2, some of the concepts were given ambiguous interpretations. Most noteworthy is the fact that the internal energy was generally conflated with the temperature, and both typically seen as a function of the velocities of the entities. In addition, only vague connections were made for some of the concepts involved in Analogy 3. Some of the concepts evolved through the exercise, resulting in a difference between the initial and final analogies. We now present the analogies in rather extensive dialogue excerpts and our qualitative analyses of what happens, as a way to show how the analogical reasoning was carried out. 
Analogy 1. Angry bees. When group B began the work of coming up with analogies, S6 immediately suggested the analogue model of angry bees in a can. The group spent the majority of the time in the group work sessions on the analogy, as seen in the large number of statements, 857, and chose it for their presentations. It covered the largest number of physical quantities (9), other concepts (5) and challenges (8) of all analogies provided by both groups. From an ownership point of view, S6 plays an important role in introducing the idea of this particular analogy, assumingly by drawing from his own experience. However, it was adopted by the entire group early on and they explored it in a cooperative fashion. Choosing a source domain that led to productive discussions is similar to Enghag and Niedderer's (2008) category of choosing a task at an appropriate level of complexity.

The analogy was categorised as having an anthropomorphic source domain, since the bees were discussed as if having emotions and a free will to act. Overall, analogies to anthropomorphic domains were found to lead to the richest discussions in the study. In addition, the 'angry bees' analogy was used to reflect the process of adiabatic expansion, but not free expansion. The central characteristic of the bees is the angriness, which the group after some discussion found to correspond to temperature in the thermodynamic model. The angriness is causally related to a number of factors, such as the volume (the more crammed, the angrier the bees), the flight speed (the angrier the bees, the faster they fly) and the frequency of crashing into each other and the walls. This structure was explored in the source and target domains, resulting in primarily coherent correspondences, and therefore, the analogy was coded as explicitly expressed and of higher-order relational structure, as exemplified in the following text excerpt, where S6 tried to establish what angriness corresponds to in the thermodynamic system:

S6: But the angriness has to be the same as the temperature, right...?

S7: Yes, it has to be that...

S6: Internal energy...

S7: It could be pressure... but that also depends on the temperature...

S6: No, the pressure has to be the result of how many times they run into the walls. /.../

S5: ... but then... it has something to do with volume... because, I mean... the less the volume, the more...

S6: It depends on that... I just mean, exactly what is the angriness... it has to be the temperature...

S7: The temperature, right...

S6: The temperature or the internal energy.

Here, S6 persisted in establishing the physical quantity that corresponds to the angriness in the source domain, while S5 and, to some degree, S7 looked for causal relationships between the angriness and other quantities within the angry bees model. In addition, the temperature and the internal energy (presumably the average per bee) largely conflate, in line with the common simplified view of temperature as identical to the average kinetic energy in ideal gases. With regards to ownership, this first excerpt also gives an example of how the students engaged in exploratory talk (Enghag et al., 2009), indicated by rapid turn-taking, incomplete sentences and sustained focus on a shared line of reasoning. Next, Group B explored how collisions are related to the 'angriness' of the bees, i.e. the temperature of the corresponding thermodynamic system:

S7: They fly a certain... at a certain velocity... they can fly to certain positions...

S8: And then they get more positions they can fly to... as you pull out the piston.

S7: But they don't get as pissed off when they get more space. /.../

S6: ... so they don't run into each other... because that is what makes them pissed off.

S7: ...run slower... so then, they don't use it, in any case...

S8: No, they won't meet with each other so often, either... so they are not so crammed... then they don't get that angry. /.../ 
S6: Well, we have to explain that first, also... that they get angry if they meet with each other. /.../ Or what keeps... what keeps them angry. /.../ Because they don't get angry, but they are kept angry, right, when they meet with each other... a constant angriness... [laughter]

S7: A constant angriness.

S5: The angriness is constant.

S6: It's like an isoangry. [laughter]

Again, we see an example of the group engaged in exploratory talk, where all participants make contributions to the development of the analogy. From a physics point of view, it also provides an interesting example of how the choice of a particular source domain influences the way of thinking about the target domain, sometimes in ways that are not sanctioned in science. For instance, Leinonen, et al. (2009) describe the misconception that collisions between particles influence the temperature or the average internal energy across the particles. This reminds of the idea expressed here that the bees have to be kept angry by a constant frequency of collisions, probably a consequence of identification with the bees as living organisms, the anthropomorphic identification. If we are not hit by our fellow humans after some time of rough-and-tumble, we will slowly calm down. If this idea regarding collisions of bees is transferred to the domain of thermodynamics, we might end up with the misconception described by Leinonen, et al, and it may be speculated whether an anthropomorphic interpretation was the origin of the idea also in their study. Another danger with the anthropomorphic reading is that the angriness of the constituent bees is mapped to temperature, which is a collective property of the entire system; a molecule by itself does not have a particular temperature. In addition, the episode further lends support to Bellocchi and Ritchie's (2011) view of analogy generation leading to merged discourse. Here, the domain of buzzing bees is merged with a microscopic model of colliding particles, bringing in features from both domains. For example, without the particle model, the students would probably not have come to think of the bees as colliding with each other or the walls. The most interesting manifestation, however, is the invention of the word 'isoangry', a hybrid across the domains. The remoteness of the domains yields a humorous effect when the formal prefix 'iso' is applied to the angriness of the bees, showing playfulness similar to that documented by Bellocchi and Ritchie.

Throughout the work, Group B (seemingly only partially playfully) expressed that they should not themselves explore where the analogy breaks down, but that it is up to the other group and the researchers to find the weak points of their analogy. This was expressed most clearly regarding their puzzlement of the constant entropy of the adiabatic process, where they assumed that the number of microstates had increased due to the increased volume:

S6: But what am I going to say [in the presentation] about the entropy? That there are more microstates, but the velocity decreases, so the probability that they end up in a state is the same...? And therefore the entropy is the same...? Do you think I should say that it's a guess...? Should we appear to...

S7: No, we claim. /.../ You should never show your weaknesses. It's up to them, in that case...

S6: What if [the researcher] starts to laugh...? [laughter] Then we say that [the lecturer] taught us so. /.../

S7: We take a chance, OK. We go: 'Everybody knows that' /.../ We go all in.

S5: 'But how did you get to that...?' 'Come on! Logic!' [laughter] 'Common sense!'

S6: 'We actually derived it.' /.../ That's our bet. /.../

S7: We just cheat.

S5: Cheat.

Here, the students were aware that they had not fully grasped how microstates relate to entropy. In addition, they felt that the analogy might have weaknesses that they had not been able to point out, themselves. From an epistemological perspective, however, in line with Heywood and Parker (1997), it is exactly this sense that the analogy is not perfect that made it open for exploration. When it comes to ownership, the group had singled out this particular 
analogy for presentation to the other group and the researchers, which contributes to them being involved in how to present what they have found out (Enghag \& Niedderer, 2008). Particularly, their sense of ownership is manifested by adopting a protective stance to their analogy, preparing rhetorical moves in response to presumptive attacks from outside.

In addition, the 'angry bees' analogy encompassed some concepts that were not found in the other analogies. For instance, the different degrees of freedom of thermodynamic systems (corresponding to translational, rotational and vibrational motion) were discussed in terms of the motion of the bees, particularly the varying ease with which they loop or spin along different axes. The individual character of each bee was reflected in pointing out that they can have different masses (referring to mother, father and baby bees), different speeds and something similar to personality or temper in that some bees get angry more easily than others. In this way, by means of exploratory talk new entities were added to the analogy, contributing to a gradually increasing complexity, interpreted as achieving a relational structure of increasing order (Gentner, 1983), but still in a primarily coherent way. This investigation of additional concepts and their relations one by one in the source domain and how they might be interpreted if transferred to the target domain in an iterative fashion follows closely the process of heuristic analogy, described by Wilbers and Duit (2006).

It was indeed challenging for group B to account for the constant entropy during volume increase, both for the thermodynamic process, as such, but also to represent it in the angry bees analogy. However, after the researchers introduced the idea of changing energy levels as a complementary contribution apart from spatial configuration to the number of microstates, the group elaborated the 'angry bees' analogy in coming up with four corresponding levels of angriness. In a way similar to the students described by Mozzer and Justi (2011), the group encompassed this refined understanding of entropy in their modified analogy:

S6: We would have to start by saying that the entropy depends on... on the one hand how many...

S8: ... how many locations the bees can be at...

S6: Yes. And on the other hand...

S8: ... on the other, how angry they are...

S5: Yes.

S7: ... what level of angriness they are at...

We cannot claim that the generation and use of the angry bees analogy was the decisive step for group B towards grasping the energetic contribution of entropy. However, at least, the analogy was involved as they tried out and expressed the new line of reasoning through which the entropy can be constant during volume increase. For the students, the elaboration of the analogy was part of making a small piece of information from the researchers their own.

Analogy 2. People at a party. The analogy that group A spent most time with (297 statements) was built on comparison of both processes with a party scenario. As a parallel to the 'angry bees' analogy of the other group, the party analogy was categorised as explicitly expressed, of higher-order relational structure and from an anthropomorphic domain. In addition, it almost encompassed the same number of concepts and challenges as the 'angry bees' analogy. In the 'angry bees' analogy, the temperature, corresponding to angriness, was the most prominent physical quantity. This was the case also for the party analogy, where temperature corresponded to the eagerness to get a seat. S4 introduced the analogy:

S4: Well, imagine that we're at a party or a pub or something. And then, we have a number of seats here... a number of tables located... People are moving all the time at a party. They don't want to get stuck too long... but you still want to be able to sit down sometimes. /.../ So some people have seats and others don't. And then, when people get up, people are very quick at trying to get the seat. When you have few 
tables, people are more eager trying to find a seat. /.../ If we now add tables, we are expanding... Then there are more seats available and then people don't have to rush to these seats.

The students saw a contrast between the processes in that a deliberate effort is needed to bring in more tables in the scenario corresponding to adiabatic expansion, but not for free expansion, where empty tables in an adjacent room suddenly become available. In addition, there were two types of locations for the people, standing up or sitting down:

S4: In the other example [free expansion]... if we imagine a big hall like this and a partition-wall between... we have a lot of tables here and a lot of tables there. /.../ All the people are gathered here... then it's, like, pretty crowded...

S3: Yes, people are standing and don't have any seats.

S4: But then, if you remove [the partition-wall], there will be more seats.

S3: Yes, more microstates.

S4: Well, but then again, people will have to be just as eager to get a seat.

S1: Right.

S4: ... since the temperature is constant.

In a similar way to how group B worked with the 'angry bees' analogy, the party analogy was introduced by one participant, but quickly adopted by the whole group, who in this excerpt contributed to exploratory talk, all characteristics of the group assuming ownership for the analogy. In all, this resulted in a rich analogy that encompassed several suitable characteristics of both processes which held the potential for establishing a relational structure of a very high order. However, at times the group had problems managing this complexity when identifying correspondences between the source and target domains at higher levels. For instance, in this excerpt they explored how the eagerness of individuals, corresponding to temperature, is affected by the knowledge whether or not there are available tables to sit at, which makes a difference between the two processes:

S3: But doesn't the entropy change then [at adiabatic expansion/addition of seats]?

S1: That's what I think is so strange...

S2: No, they have less seats... they have a smaller volume for their seats...

S3: What? I mean, now we have just looked at the microstates of the seats...

S4: Mhm...

S3: But if we take away seats and nothing else happens... if we take away seats and decrease the volume...

$/ . . . /$ the volume increases or the volume decreases... well, that depends on which way it goes...

Here, S3 had difficulties sorting out if taking away seats in the party setting corresponds to increased or decreased volume of the system, leading to an ambiguity in the correspondences in the analogy. In our view, the reason is that there is no correspondence to standing versus sitting in terms of different types of locations or microstates in the ideal-gas model. There is only one type of location that is either occupied or not. This characteristic of the analogy would have been more suitable for other thermodynamic phenomena, but is overly complex for the target domain at hand. Yet, again, this feeling of not quite having worked out all correspondences of the analogy still resulted in exploratory talk between the participants. In addition, even though they were aware of not having identified all correspondences of the analogy, the group chose to present the source domain and the analogy to the other group and the researchers, a sign of having assumed ownership of the analogy.

Analogy 3. Models of balls. While the party analogy resulted in a complexity that was difficult to handle, the tactic of using idealised models of one or a few balls bouncing against walls in a frictionless way proved more helpful for both groups. This was particularly useful when it came to explaining the constant temperature in the free expansion process, which 
initially was seen as puzzling. In contrast to the bee and party analogies, these analogies were similar to taught models and taken primarily from the domain of mechanics within physics. For instance, group B used a model of balls bouncing on walls in free space:

S7: Maybe it's in... in space... you shoot out a ball... then they go... [gestures crossing and bouncing balls] /.../ ...weightlessness... then they just go like this... 'ding', 'ding' [sound effect and gestures crossing balls] /.../

S8: You put up two walls on the moon and then we send in a ball...

S7: Yes, but then you have the gravity.../... A corridor.../.../A corridor in the middle of space... then you throw in balls that start to bounce like this... [gesture of crossing and bouncing balls with sound effects] 'ding', 'ding' .... and then, like: 'poh' [a wall is suddenly removed] /.../ Then, they will start to go in this way instead [gesture of travelling a longer distance before bouncing] ... at the same speed. /.../

S6: But if the temperature is constant, of course they have the same speed.

S7: OK, but how... We have to be able to explain it in some way... why it is so...

By introducing weightlessness and ignoring air resistance, the students realised that the speed of the particles would remain unchanged when a wall was removed. Although reminding of ideal models of elastic collisions in mechanics, the situation of the problem in free space made them aware of the idealisations made, as compared to an earth scenario. S6 saw it as self-evident that constant temperature implies constant speed, probably based on previous teaching on the kinetic theory of gases, but S7 expressed the need for a deeper explanation. Yet again, ownership was manifested in the form of exploratory talk and the groups choosing to present their idealised models to each other and the researchers.

Analogy 4. Lice. Beside the ideal models of balls, Group A used an analogy of lice jumping from the head of one person to another to explain the constant temperature in free expansion. In contrast to the three analogies above, the lice analogy was not a self-generated analogy, but it had been presented by the lecturer in their previous course in thermodynamics in order to explain thermal equilibrium, and may be seen as an extension of the 'dog-flea model', studying the distribution of the population of fleas jumping between two dogs. Nevertheless, the students had the possibility to recruit all their previous experience in coming up with analogies, and the choice of this particular analogy is similar to the approach of selecting a task that looks interesting and of appropriate difficulty from a list of alternatives (Enghag \& Niedderer, 2008). All elements stated in the source domain had an explicit counterpart in the target domain, which was quickly demonstrated in their short group presentation where they also aimed at capturing both the energy and the spatial configuration contributions to entropy:

$\mathrm{S} 1$ : Yes, but this is the same as the one [the lecturer] brought up in the lecture... about energy conservation... or the energy problem ... that you can see ... see entropy as if I have lice in my hair... and [S2] has no lice... So now we are in example 2 [free expansion], right... and then, if we bump into each other, then half of the lice will jump over to [S2]... and then the disorder is higher, so the entropy has increased... /.../ ...because they are distributed... and the pressure is halved, because they don't bite me as hard, since there are not as many... and what more did we say...?

S2: Pressure... per area unit... there will be a larger area...

S3: They jump just as fast throughout...

S1:...so the speed will be the same, too...

In spite of this promising start where they found many correspondences and did not run into any great inconsistencies between the source and target domains, this analogy was not elaborated much further. They did not deal with other challenges apart from the constant temperature (in contrast to, for example, the eight challenges in relation to the angry bees and the seven challenges of the party analogy). One possible explanation for why the analogy was not elaborated further is that it was assumed to be unproblematic in that all relevant 
correspondences made sense and that all participants shared the same view of it. However, in the further investigation of what corresponds to the pressure in the analogy, S1 provided yet another example of merged language (Bellocchi \& Ritchie, 2011) in the form of 'bite pressure': "Well, if you imagine that [the lice] get evenly distributed... and if I have a lot of lice and [S2] has none, then the bite pressure on me will halve if [S2] takes half of my lice".

\section{Discussion}

We first revisit the research questions in the light of the presented results of study and round up with educational implications of the study.

\section{What Characterises the Analogical Reasoning in a Group Exercise when Students are Asked to Come up with Analogies for Thermal Phenomena?}

Overall, the group work was characterised by the participants 'talking science' (Lemke, 1990) throughout the exercises, in terms of focusing on the tasks of exploring the phenomena and coming up with analogies for them. In support of Aubusson and Fogwill's (2006) findings, invitation of students to develop analogies cooperatively encouraged them to express and develop their own conceptions of the phenomena. A large number of potential source domains were brought up (see Table 1), but the degree to which they were elaborated differed considerably. Some of the source domains were briefly mentioned by one of the students but was not picked up by the others and quickly forgotten, e.g. enclosed cows. In other cases, the students reminded each other of analogies known from previous teaching (such as the analogy with the lice above) or known modelling approaches (such as models of balls). The two analogies that were elaborated to the greatest depth (the angry bees and the party) and for Group B represented the bulk of the discussion, however, both were initiated by one of the students but quickly adopted by the other members of the group. The question is why these particular analogies generated the richest discussions.

In line with Heywood and Parker (1997), the 'angry bees' analogy was an example of how an analogy with many correspondences between the source and target domains generated a rich discussion. Nevertheless, the relationship between the number of entities that is mapped between the source and target domains and the richness of the discussion is not a clear-cut issue. In the case of the party analogy, the situation became too complex, and Group A could not manage the structure in a coherent way, with the result that they could not draw inferences with regards to the target domain and the discussion petered out. In contrast, in the lice analogy, Group A established the correspondences between the domains for a crucial set of entities quickly, which at first sight would seem to be a successful example. As pointed out by Heywood and Parker, however, identification of break-down is regarded more productively as an important trigger for engagement with an analogy, rather than as a sign of a poor analogy. The lice analogy in the present study is an example of an analogy with an almost too good match between the source and target domains. No break-down or challenges were encountered, and consequently, the discussion did not take off.

The framework on analogical reasoning developed by Wilbers and Duit (2006) may help us explain why certain analogies were elaborated further than others. In the case of the lice analogy, the students did not feel invited to investigate where the analogy would lead. Starting as a teacher-generated post-festum analogy, the students did not take on the challenge of making it their own heuristic analogy and investigating what hypotheses it might result in. In the case of the party analogy, however, the students approached the task in the heuristic mode of analogical reasoning and managed to create a couple of interesting correspondences and hypotheses, but the process ended after only a few iterations, due to the complexity and difficulty in establishing new connections between the domains. In the case of the familiar ideal models of balls, they served the purpose of explaining the aspects of the phenomena that 
had had been difficult to account for, but did not stimulate new hypotheses in an iterative fashion. Other comparisons got stuck even earlier and were limited to the brief association. Only when it came to the angry bees did the students hang on to a large number of iterations, gradually adding more details to the analogy in a coherent and constructive way.

The result that all analogies brought up in this study were built on microscopic models of thermodynamic systems lends support to Reif's (1999) view that it is difficult to visualise concepts in macroscopic thermodynamics. Instead, anthropomorphic comparisons of particles with sentient beings led to deep elaborations and the idealised models of balls proved particularly useful in coming to terms with the constant temperature in the free expansion process. However, the reluctance to use macroscopic explanations may have hindered the reasoning and problem-solving. The constant entropy in adiabatic expansion is a consequence of a reversible process without heat exchange. The constant temperature in free expansion is due to the ideal gas assumption and constant internal energy, since there is no exchange of heat or work. Such macroscopic lines of reasoning would have been potentially more powerful in making sense of these two processes.

Glynn (1989) and Zook (1991) warn for the potential outcome of teaching with analogies that misconceptions might be formed. In the current study, a case in point was the anthropomorphic idea that collisions are required for angry bees to remain angry. This idea was transferred to the domain of thermodynamics where Group B argued that particles have to collide to keep the temperature constant, a misconception previously identified by Leinonen et al. (2009). Another example was the hypothesis that entropy is related to the change of microstates, which was a reasonable idea given the background information, but not in line with current thermodynamics theory. Here, the researchers intervened and introduced the idea of energy levels in relation to microstates. If the students had been allowed to elaborate this hypothesis further, it might well have been reinforced, so that a misconception would have been established as a consequence of the analogy exercise. The way the groups identified challenges, but also came to terms with most of them, is a theme we would like to develop in future research. The 'party' analogy is another related example of time spent that probably was not effective for learning, but not due to misconceptions being formed, but rather because the group did not come to constructive conclusions. However, we did not find support for Zook's (1991) prediction that selection of the source domains of the analogies generated by the learners themselves would be particularly problematic. Instead, we adhere to the view of Heywood and Parker (1997) that imperfect analogies may contribute to richer discussions, provided that time is given to scrutinise those imperfections. Similarly, the groups did not run into detrimental group dynamics when generating their own analogies, as previously reported by Yerrick et al. (2003), but managed to hold focus on the task of creating new analogies and investigate their relations to the two thermodynamic processes. One possible reason for why the students were comparatively successful in the generation of analogies may be that the tasks were presented at a late stage in relation to the teaching of the subject. They are likely to have been guided in their thinking by known microscopic models and were thereby constrained in their associations to previously encountered phenomena.

\section{How is Ownership of Learning Manifested as Students Come up with Analogies?}

In general, in the present study, similar to the findings of Enghag et al. (2009), there were few examples of individual students bringing in issues that were of particular interest to themselves, but not to the others of the group. Instead, if a potential source domain was brought up, it was either adopted by the groups as a whole or not elaborated at all. This emphasis of the group dimension was even expressed when it came to identifying particular difficulties in understanding the phenomena and resolving these difficulties, activities that Enghag and Niedderer (2008) assigned to the individual dimension of ownership. Hence, 
ownership was primarily expressed at the group level. The selection of a suitable source domain is a direct way for students to choose their object of study, one of the criteria for group ownership of learning (Enghag \& Niedderer, 2008). Next, the students have to assume ownership of the analogy, since it has to be either explored, with assessment of its merits and shortcomings, or discarded. In the present study, this ownership of the analogy is emphasised most clearly in the 'angry bees' analogy, where it even develops into a protective stance, in that it is up to people outside the group to find the weaknesses of the analogy. This required responsibility may be one of the reasons for the students spending so much time and coming to such structural depth with their own analogies.

Blanchette and Dunbar (2000) argue that participants' accounts of self-generated analogies have a clearer relational focus than their accounts of teacher-generated analogies, due to their differing understanding of the relational structures. In the present study, we also found that self-generated analogies were elaborated with a clear focus on relational structures. However, the reasons for why teacher-generated analogies were not developed to the same structural depth in the present study are quite different from those identified by Blanchette and Dunbar. For example, in the presentation of the lice analogy, the participants quickly pointed out correspondences between the source and target domains in a coherent way. If they had only discerned the surface attributes of the presented analogy during teaching, they would not have found it helpful and would not have used it in this subsequent setting. Instead, one possible reason is that they took for granted that the other group members had understood the analogy in the same way as themselves, and that therefore there was no need to elaborate it further and negotiate the finer details. By selecting a particular analogy, the teacher had sanctioned it and it became less likely that the students would scrutinise it. With their own analogies, on the other hand, the students were more aware that the sources are not perfect matches to the targets. In terms of ownership, they made active choices of which analogies to explore and assess. At the same time, in the case of the angry bees, the sense of ownership was maybe taken too far in that the protective attitude seems to have hindered them in identifying points of break-down. From another point of view - how the task was framed the participants had realised from the introduction of the task that accounts of their own analogies would be more appreciated by the researchers than the teacher's analogies, but also subject to a more critical analysis in the presentations. Therefore the students dedicated more time and effort to them, resulting in greater structural depth. Our data supports Blanchette and Dunbar's (2000) results that deeper relational structures are uncovered in the work with selfgenerated analogies, compared to work with teacher-generated analogies. However, while they find the reason primarily in the learners' cognitive abilities in interpreting the teachergenerated analogies, in our case, other meta-cognitive and affective aspects were more decisive. Nevertheless, the conclusion is the same: work with self-generated analogies provides a fertile soil for focus on deep relational structures in analogical reasoning.

\section{Contributions to the Research on Analogies in Science Education}

The findings in the present study add to the research on the use of self-generated analogies in science education, which still is sparse, particularly when it comes to social, collaborative settings. In line with Zook (1991) and Yerrick et al. (2003), we provide evidence that students asked to come up with analogies by themselves may express and possibly even reinforce misconceptions of the phenomena with which they interact. Accordingly, at times the students provided idiosyncratic, personal explanations, not in line with the received view in science. Nevertheless, overall, we side with the predominantly encouraging view of for example Aubusson and Fogwill (2006) on collaborative generation of analogies, due to the fact that with moderate guidance the students were able to make their accounts more in line with the received view. What is particularly novel, however, is the 
recognition of the role of ownership that comes along with the creative aspects of selfgenerated analogies, which provides complementary explanations to those of Blanchette and Dunbar (2000). In addition, the plethora of analogies that the students came up with has reached a breadth and, at times, depth not previously reported, to our knowledge, giving evidence of how the creativity of students may be further exploited in science education.

\section{Limitations of the Study}

The possibilities to generalise the results of the present study to other students, settings and objects of study beyond thermodynamics are obviously limited by the small number of participants and short exposure. The cooperativeness of the students and their ability to encourage contributions from each other without digressing away from the considered thermal phenomena, in contrast to for example the findings of Yerrick et al. (2003), may have been purely coincidental. In particular, the predominant focus on microscopic analogies for the phenomena may mirror a personal preference among these particular students or, alternatively, may have been biased by microscopic features being included in the task descriptions, such as the average velocity of particles and collisions between them. However, the issue of generalisability may also be considered in the broader light of our overall research program to investigate self-generated analogies for thermal phenomena, including also 7-8year-olds (Haglund, Jeppsson, \& Andersson, in press). Taken together, these two studies support the idea of the use of self-generated analogies as a productive and largely underexploited resource for expression and development of scientific understanding.

\section{Educational Implications}

In the present study, we show that the use of self-generated analogies is a possible way to make students assume ownership of their learning, by engagement in group work and induce them to 'talk science' (Lemke, 1990), something that unfortunately is too rare in the traditional physics classroom. Specifically, self-generated analogies tend to be elaborated into a greater structural depth than teacher-generated analogies, and are therefore in line with Gentner's (1983) structural perspective on analogy, particularly when described in terms of bootstrapping (Kurtz et al., 2001). However, we also acknowledge the creative aspect of analogical reasoning, emphasised by Wilbers and Duit (2006). In addition, we support Pittman's (1999) view that the use of self-generated analogies is a potential approach for identifying challenges to learning science concepts but also for learners to come to terms with such challenges. Furthermore, the fact that students in both groups in our investigation were able to generate and handle many different analogies which emphasised different aspects of the same phenomena shows that self-generated analogies is a possible way to generate multiple analogies, as proposed by Spiro, Feltovich, Coulson and Anderson (1989). These findings complement the results from prior studies (e.g. James \& Scharmann, 2007), where the use of student-generated analogies led to higher learning gains than teacher-generated analogy or no analogy approaches. In these respects, student-generated analogies may be useful both as an instructional tactic and a research tool.

Another result was that often more questions were raised by the students than answers given, in support of the view of Wilbers and Duit (2006) on heuristic analogies in science learning. Consequently, the use of self-generated analogies can be seen as a method for generating hypotheses in a constructivist framework and for inquiry based learning, which can lead to further exploration. We here adhere to the view of Heywood and Parker (1997) that richness of the discussions is one of the main objectives of the exercise, rather than finding the analogy with the perfect match between the source and target domains. Similarly, we support Enghag et al. (2009) in encouraging exploratory talk, with its character of questioning and sustained focus on the science content. Still, the question of what type of 
analogy is most fruitful for learning is a delicate issue. On one hand, the 'perfect analogy' does not stimulate discussion, but on the other, all discussion does not lead to deeper understanding. The teacher is crucial in managing the process of learning and will have to intervene when analogies tend to become too complex or when the students end up in idiosyncratic explanations which are not in line with the current science view.

Finally, the introduction of self-generated analogies clearly does not solve all challenges to science teaching. As Clark (2006) argues, students need guidance in order not to focus too much on their idiosyncratic explanations when trying to reconcile their previous understanding and new experiences. Duit, Roth, Komorek and Wilbers (2001) propose that learning science by use of analogy is like passing between Scylla and Charybdis and it is indeed a journey through dire straits. In their critical reading of the Odyssey, Adorno and Horkheimer (1997) claim: "From Homer to modern times, the dominant spirit wishes to steer between the Scylla of a return to mere reproduction and the Charybdis of unfettered fulfilment". Applied to the field of analogical reasoning, we may end up wrecking against the Scylla of transmissive teaching, but there is also Charybdis, the enticing maelstrom of idiosyncratic explanations. As recognised by Adorno and Horkheimer, however, when Odysseus went clear of these obstacles on his long journey back home, he assumed responsibility for his own fate. In this respect, he both defied the whims of the gods and tried to control the forces of nature as an early representative of the modern project of enlightenment, a humbling counterpart to our students' science learning endeavour.

\section{References}

Adorno, T. W., \& Horkheimer, M. (1997). Dialectic of enlightenment. London, UK: Verso.

Aubusson, P. J., \& Fogwill, S. (2006). Role play as analogical modelling in science. In Aubusson, P. J., Harrison, A. G. \& Ritchie, S. M. (Eds.), Metaphor and Analogy in Science Education (pp. 93-104). Dordrecht, NL: Springer.

Baierlein, R. (1994). Entropy and the second law: A pedagogical alternative. American Journal of Physics, 62(1), 15-26.

Bellocchi, A., \& Ritchie, S. M. (2011). Investigating and theorizing discourse during analogy writing in chemistry. Journal of Research in Science Teaching, 48(7), 771-792.

Blanchette, I., \& Dunbar, K. (2000). How analogies are generated: The roles of structural and superficial similarity. Memory \& Cognition, 28(1), 108-124.

Brosseau, C., \& Viard, J. (1992). Quelques réflexions sur le concept d'entropie issues d'un enseignement de thermodynamique. Enseñanza de las Ciencias, 10(1), 13-16.

Bucy, B. R. (2007). Investigations of student understanding of entropy and mixed second-order partial derivatives in upper-level thermodynamics. Unpublished Doctoral Dissertation, University of Maine, Orono, ME.

Clark, D. (2006). Longitudinal conceptual change in students' understanding of thermal equilibrium: An examination of the process of conceptual restructuring. Cognition and Instruction, 24(4), 467-563.

Clement, J. (1987). Generation of spontaneous analogies by students solving science problems, International Conference on Thinking (3rd), Honolulu, HI, January 4-8. Honolulu, HI.

Clement, J. (1988). Observed methods for generating analogies in scientific problem solving. Cognitive Science, 12(4), 563-586.

Dudley-Marling, C., \& Searle, D. (1995). Who owns learning? Questions of autonomy, choice, and control. Portsmouth, NH: Heinemann.

Duit, R., Roth, W.-M., Komorek, M., \& Wilbers, J. (2001). Fostering conceptual change by analogies - between Scylla and Charybdis. Learning and Instruction, 11(4-5), 283-303.

Enghag, M., Gustafsson, P., \& Jonsson, G. (2009). Talking physics during small-group work with content-rich problems - analysed from an ownership perspective. International Journal of Science and Mathematics Education, 7(3), 455-472.

Enghag, M., \& Niedderer, H. (2008). Two dimensions of student ownership of learning during small-group work in physics. International Journal of Science and Mathematics Education, 6(4), 629-653.

Fuchs, H. U. (1987). Entropy in the teaching of introductory thermodynamics. American Journal of Physics, 55(3), 215-219.

Gentner, D. (1983). Structure-mapping: A theoretical framework for analogy. Cognitive Science, 7(2), 155-170. 
Glynn, S., M. (1989). The teaching with analogies model. In Muth, K. D. (Ed.), Children's comprehension of text: Research into practice (pp. 185-204). Newark, DE: International Reading Association.

Haglund, J., Jeppsson, F., \& Andersson, J. (in press). Young children's analogical reasoning in science domains. Science Education.

Haglund, J., Jeppsson, F., \& Strömdahl, H. (2010). Different senses of entropy - Implications for education. Entropy, 12(3), 490-515.

Hesse, M. B. (1966). Models and analogies in science. Notre Dame, IN: University of Notre Dame Press.

Heywood, D., \& Parker, J. (1997). Confronting the analogy: primary teachers exploring the usefulness in the teaching and learning of electricity. International Journal of Science Education, 19(8), 869-885.

James, M. C., \& Scharmann, L. C. (2007). Using analogies to improve the teaching performance of preservice teachers. Journal of Research in Science Teaching, 44(4), 565-585.

Jeppsson, F., Haglund, J., \& Strömdahl, H. (2011). Exploiting language in teaching of entropy. Journal of Baltic Science Education, 10(1), 27-35.

Kaper, W., \& Goedhart, M. (2005). A three-phase design for productive use of analogy in the teaching of entropy. In Boersma, K., Goedhart, M., de Jong, O. \& Eijkelhof, H. (Eds.), Research and the Quality of Science Education (pp. 297-308). Dordrecht, The Netherlands: Springer.

Kurtz, K. J., Miao, C.-H., \& Gentner, D. (2001). Learning by analogical bootstrapping. Journal of the Learning Sciences, 10(4), 417-446.

Lambert, F. L. (2002). Disorder - A cracked crutch for supporting entropy discussions. Journal of Chemical Education, 79(2), 187-192.

Leinonen, R., Räsänen, E., Asikainen, M., \& Hirvonen, P. E. (2009). Students' pre-knowledge as a guideline in the teaching of introductory thermal physics at university. European Journal of Physics, 30(3), 593-604.

Lemke, J. L. (1990). Talking science. Language, learning and values. Norwood, NJ: Ablex.

Loverude, M. E., Kautz, C. H., \& Heron, P. R. L. (2002). Student understanding of the first law of thermodynamics: Relating work to the adiabatic compression of an ideal gas. American Journal of Physics, 70(2), 137-148.

Meltzer, D. E. (2004). Investigation of students' reasoning regarding heat, work and the first law of thermodynamics in an introductory calculus-based general physics course. American Journal of Physics, 72(11), 1432-1446.

Milner-Bolotin, M. (2001). The effects of topic choice in project-based instruction on undergraduate physical science students' interest, ownership, and motivation. Unpublished Doctoral Dissertation, University of Texas, Austin, TX.

Mozzer, N. B., \& Justi, R. (2011). Students' pre- and post-teaching analogical reasoning when they draw their analogies. International Journal of Science Education, 1-30.

Pittman, K. M. (1999). Student-generated analogies: Another way of knowing? Journal of Research in Science Teaching, 36(1), 1-22.

Reif, F. (1999). Thermal physics in the introductory physics course: Why and how to teach it from a unified atomic perspective. American Journal of Physics, 67(12), 1051-1062.

Savery, J. R. (1996). Fostering student ownership for learning in a learner centered instructional environment. Unpublished Doctoral Dissertation, Indiana University, Bloomington, IN.

Schoultz, J., Säljö, R., \& Wyndhamn, J. (2001). Heavenly talk: Discourse, artifacts, and children's understanding of elementary astronomy. Human Development, 44(2-3), 103-118.

Spiro, R. J., Feltovitch, P. J., Coulson, R. L., \& Anderson, D. K. (1989). Multiple analogies for complex concepts: Antidotes for analogy-induced misconception in advanced knowledge acquisition. In Vosniadou, S. \& Ortony, A. (Eds.), Similarity and analogical reasoning. (pp. 498-531). Cambridge, UK: Cambridge University Press.

van Merriënboer, J. J. G., Shuurman, J. G., de Croock, M. B. M., \& Paas, F. G. W. C. (2002). Redirecting learners' attention during training: effects on cognitive load, transfer test performance and training efficiency. Learning and Instruction, 12(1), 11-37.

Wilbers, J., \& Duit, R. (2006). Post-festum and heuristic analogies. In Aubusson, P. J., Harrison, A. G. \& Richie, S. M. (Eds.), Metaphor and Analogy in Science Education (pp. 37-49). Dordrecht, NL: Springer.

Wong, E. D. (1993a). Self-generated analogies as a tool for constructing and evaluating explanations of scientific phenomena. Journal of Research in Science Teaching, 30(4), 367-380.

Wong, E. D. (1993b). Understanding the generative capacity of analogies as a tool for explanation. Journal of Research in Science Teaching, 30(10), 1259-1272.

Yerrick, R. K., Doster, E., Nugent, J. S., Parke, H. M., \& Crawley, F. E. (2003). Social interaction and the use of analogy: An analysis of preservice teachers' talk during physics inquiry lessons. Journal of Research in Science Teaching, 40(5), 443-463.

Young, H. D., Freedman, R. A., \& Sears, F. W. (2003). Sears and Zemansky's university physics: with modern physics (11th ed.). San Francisco, CA: Pearson Education. 
Zook, K. B. (1991). Effects of analogical processes on learning and misrepresentation. Educational Psychology Review, 3(1), 41-72.

Supplementary Information linked to the online version of the paper at Wiley-Blackwell (http://onlinelibrary.wiley.com/journal/10.1002/(ISSN)1098-2736): Methods Supplement. 


\section{Self-Generated Analogies - Background Information}

Analogies are common in education. A typical purpose is that the students are supposed to lean something about a new domain through comparing with or drawing conclusions from another, more familiar domain. One example is "The atom is like a solar system". In this analogy, the abstract, invisible and supposedly unfamiliar atomic structure is compared to a more concrete and familiar domain, i.e. celestial bodies in motion. Typically, you want to put forward structural similarities between the domains, and not just attributes or eye-catching characteristics. In the example of the atom, you want to show that electrons correspond to planets, rotating around a much larger central atomic nucleus/sun, and that there is much empty space between them. At a higher level, you can show mathematical similarities, such as the proportionality of the force to charges/masses and inverse proportionality to the square of the distance. In contrast, you do not want the students to believe that the atomic nucleus is warm and yellow, or that the electrons have different colours or sizes.

Since an analogy is a representation of a phenomenon, where certain characteristics are brought to the foreground and others played down, it is never a perfect image. The analogy breaks down somewhere, at which point conclusions from the known domain cannot be transferred to the new domain. For instance, the solar system does not give a particularly good quantum physics explanation of the atom.

In studies of students' learning through interpretations of analogies that their teachers or researchers have given them, it has been found that they have difficulties finding the intended structural similarities. The students get stuck with surface similarities between the domains, such as the assumed yellow colour of the atomic nucleus. They also have difficulties transferring knowledge provided from an analogy to a new, third, previously unknown domain. Duncker's radiation problem is an example in case. Participants are confronted with a general's problem of capturing a fortress and the solution is to divide the forces so that they approach the fortress from different directions for a simultaneous attack. Next, the participants are presented the situation of treating a tumour with radiation, but with the complication that single rays are too weak to affect healthy tissue and the tumour, while a bundle of rays would damage both. The solution is to use the fortress as an analogous model to grasp that the rays should come from different directions and converge in one spot. Studies have shown that remarkably few participants use the intended analogy spontaneously to solve the problem. More participants use it if they are actively reminded of the previously handled problem.

This difficulty in adopting analogies stands in contrast to our daily lives. Studies have fond that we use analogies spontaneously in orienting ourselves in relation to new situations. One example is scientists who use analogies in creative work, but also students have been found to use analogies they come up with themselves as a natural way to approach a new area of study.

A number of science education researchers have found that one reason for the difficulty in grasping analogies is that they are presented by others. The participants are assumed to both know the analogous domain (e.g. the solar system) and to focus on the intended structural similarities. One way to come to terms with these challenges is to ask the learners themselves to come up with and evaluate analogies as part of education of a new phenomenon or a new domain. This approach is in line with a constructivist tradition, according to which learning is assumed to be based in the learner's previous knowledge. 


\section{Exercise Set-Up}

- Introduction to analogies and self-generated analogies

- Introduction to two thermodynamic processes

- Group exercise to understand and find analogies for the two processes

o Read through the descriptions of the processes in order to establish a shared view in the group. What is difficult to understand?

o 'Brain storming' in order to generate several, different analogies (with particular regard to entropy)

o Select a few of the analogies for the processes that you in the group find particularly good and/or interesting

- Which aspects of the processes do you illustrate?

- Which strengths and weaknesses do the analogies have?

- Where do the analogies break down?

- Presentation of the analogies in the whole group and feedback from the other participants

o Present your analogies to the other participants

o Give response to the other participants' analogies

- Further development of analogies back in small groups

o How can your analogies be developed/modified?

o Have you come to think of entirely new analogies?

- Debriefing and discussion in the whole group

o Short presentation of modified and new analogies

o Have you learnt anything about the two processes in the exercise?

o How can analogies, and particularly self-generated analogies be used in a teaching situation?

o What merits and shortcomings do teaching with analogies have?

o How can you 'improve the odds' for successful teaching with analogies? 


\section{Thermodynamic Processes}

\section{Termodynamiska processer}

Process 1. Adiabatic expansion

An ideal gas is kept in a container by a frictionless piston. The gas has amount of substance $n$, temperature $\mathrm{T}$, internal energy $\mathrm{U}$, pressure $\mathrm{p}$, volume $\mathrm{V}$ and entropy $\mathrm{S}$. Let the gas expand slowly, adiabatically (i.e. no heat $\mathrm{Q}$ is exchanged with the environment) and reversibly (i.e. so that the process "can go in the other way" to restore the original state) by retracting the piston. As the piston retracts, work $\mathrm{W}$ is performed by the gas on the environment, which means that the internal energy $U$ of the gas decreases. At the same time, the volume $\mathrm{V}$ increases and the pressure $\mathrm{p}$ decreases. The temperature $\mathrm{T}$ decreases. The average velocity of the gas particles decreases, because they will have a lower velocity after collisions with the withdrawing piston. The entropy does not change during the process, since no heat has been exchanged with the environment and the process is reversible, a situation represented by the following relation: $\mathrm{dS}=\mathrm{dQ} / \mathrm{T}$.

\section{Process 2. Free expansion}

An ideal gas is kept in one half of an isolated container separated by a thin wall. There is a vacuum in the other half. The gas has amount of substance $n$, temperature $T$, internal energy $U$, pressure $p$, volume $V$ and entropy $S$. After the instantaneous removal of the wall, the gas expands freely in the entire container. No work $W$ or heat $Q$ is exchanged with the surroundings, and hence, the internal energy remains constant. As a result, the volume of the gas is doubled and the pressure is halved. Since the particles collide with the stationary walls, their average velocity does not change. The temperature $T$ is constant, but the entropy $S$ increases.

\section{Task:}

- Establish a shared understanding of Processes 1 and 2. What is difficult to understand?

- Create analogies for Processes 1 and 2, which explain the phenomena as a whole with a particular emphasis on the development of the entropy. 